\title{
Functional Screening Yields a New $\beta$-1,4-Endoglucanase Gene from Heterodera glycines that May be the Product of Recent Gene Duplication
}

\author{
Yitang Yan, ${ }^{1}$ Geert Smant, ${ }^{2}$ and Eric Davis ${ }^{1}$ \\ ${ }^{1}$ Department of Plant Pathology, Box 7616, North Carolina State University, Raleigh 27695, U.S.A.; \\ ${ }^{2}$ Department of Nematology, Wageningen University and Research Center, Binnenhaven 10, 6709 PD \\ Wageningen, The Netherlands \\ Accepted 2 October 2000.
}

Clones with secreted cellulolytic activity were identified when a cDNA library constructed from poly A(+) RNA of preparasitic second-stage juveniles of Heterodera glycines, the soybean cyst nematode, was expressed in the $E s$ cherichia coli SOLR strain and overlaid with a carboxymethylcellulose (CMC) substrate. Twenty CMC-degrading clones were analyzed, and all were either identical or strongly similar to a $\beta$-1,4-endoglucanase gene (HG-eng-2), previously isolated from $\mathrm{H}$. glycines. A subgroup of identical "HG-eng-2-like" clones had considerable differences in the $5^{\prime}$ untranslated region compared with HG-eng-2 and were designated HG-eng-3. One $\boldsymbol{H}$. glycines genomic clone contained HG-eng-2 and HG-eng-3 full-length genes, separated by a distance of approximately $8 \mathrm{~kb}$, and a second genomic clone contained two copies of HG-eng-2, separated by approximately $6.5 \mathrm{~kb}$, suggesting the presence of endoglucanase gene clusters in $\mathrm{H}$. glycines. The HG-eng-2 and HG-eng-3 genes were in opposite transcriptional orientation, with considerable nucleotide differences in their 5 ' flanking regions. The highly conserved nucleotide sequence in the introns and exons and their close proximity within the genome suggest that HG-eng-2 and HG-eng-3 are the products of recent gene duplication and inversion.

Additional keywords: cellulase, evolution, parasitism, pathogenesis, plant-parasitic nematode.

The ability of microorganisms to degrade the complex polysaccharides of plants is of primary interest in terms of microbial ecology, industrial applications, and plant pathogenesis (Coughlan 1985). The hydrolysis of complex carbohydrates by secreted enzymes enables some plant pathogens to gain entry into plant tissues and to utilize the products of polysaccharide

Corresponding author: E. Davis; Telephone: +1-919-515-6692; Fax: +1-919-515-7716; E-mail: eric_davis@ncsu.edu

Sequence data deposited in GenBank: AF006053 (HG-eng-2 cDNA clone), AF044210 (HG-eng-3 cDNA clone), AF006052 (HG-eng-1 cDNA clone), AF052734 (HG-eng-2 genomic clone), AF056048 (HGeng-3 genomic clone). degradation for pathogen nutrition (Barras et al. 1994). Previous investigations have suggested the existence of a battery of hydrolytic enzymes within plant-parasitic nematodes that have the ability to degrade complex plant carbohydrates (Deubert and Rohde 1971). Until recently, evidence for enzymes such as cellulases and pectinases of nematode origin remained elusive.

Two genes encoding $\beta$-1,4-endoglucanases (cellulases) were recently cloned from two species of plant-parasitic cyst nematodes, and were the first cellulases reported to be endogenous to animals (Smant et al. 1998). The cyst nematode species Globodera rostochiensis and Heterodera glycines each possess one endoglucanase gene (GR-eng-1 and HGeng-1, respectively), encoding a predicted $5^{\prime}$ secretion signal peptide, catalytic domain, peptide linker of repeat amino acid sequence, and a $3^{\prime}$ cellulose-binding domain (CBD). G. rostochiensis has a second endoglucanase gene (GR-eng-2) that does not contain the $\mathrm{CBD}$, and $H$. glycines has a second endoglucanase gene (HG-eng-2) that does not contain either the CBD or peptide linker (Smant et al. 1998). Sequence of the genomic clones revealed an intron-exon structure that was consistent with known eukaryotic genes as well as identical intron splicing positions among eng- 1 and eng- 2 that appeared between both cyst nematode species (Yan et al. 1998). GReng-1 and GR-eng-2 have high nucleotide similarity among the corresponding introns of each gene and within the $5^{\prime}$ untranslated region $\left(5^{\prime} \mathrm{UTR}\right)$ of each gene, whereas the nucleotide sequence of the $5^{\prime}$ UTR and introns between HG-eng-1 and HG-eng- 2 are more divergent. Although the putative promoter regions of all cyst endoglucanase genes have typical eukaryotic consensus cis elements, the coding regions of each nematode endoglucanase gene have strong similarity to bacterial family 5 endoglucanases and no homology to fungal or plant endoglucanases. In situ localization of endoglucanase transcription and translation products within the secretory esophageal gland cells of cyst nematodes confirmed the endogenous origin of the nematode endoglucanases (de Boer et al. 1999; Smant et al. 1998). In planta secretion of endoglucanase by $\mathrm{H}$. glycines and the activity of the nematode endoglucanase genes have been observed in motile nematode stages during plant root infection (De Boer et al. 1999; Wang et al. 1999). 
The isolation of the first cyst nematode endoglucanase genes was a laborious process (Smant et al. 1998). The at first unidentified protein was affinity-isolated with a nematode esophageal gland-specific monoclonal antibody (de Boer et al. 1996). The N-terminal amino acid sequence was obtained from the purified protein, and degenerate primers were designed from the amino acid sequence to obtain the resultant endoglucanase cDNA from cyst nematode mRNA with $3^{\prime}$ rapid amplification of cDNA ends ( $3^{\prime}$ RACE). Here we describe the isolation of cDNA clones on the basis of their ability to express enzymes that hydrolyze specific complex carbohydrate substrates, a relatively simple functional screening approach to isolate potential parasitism genes without prior sequence information. The endoglucanase substrate, carboxymethylcellulose (CMC), has been used successfully in colorimetric assays to isolate endoglucanase clones from bacteria and fungi (Malburg and Forsberg 1993; Mateos et al. 1992; Saloheimo et al. 1994). The endoglucanases of cyst nematodes also have demonstrated the ability to hydrolyze CMC (Smant et al. 1998). Here we report the isolation of a HG-eng-2 variant (designated HG-eng-3) from a $H$. glycines cDNA library that was expressed in Escherichia coli and screened for the ability to degrade CMC. Analysis of the genome organization of HG-eng-2 and HG-eng-3 suggests a recent endoglucanase gene duplication event in $H$. glycines.

\section{RESULTS}

Functional screening of a $\mathrm{H}$. glycines

cDNA expression library in $\boldsymbol{E}$. coli.

pBluescript II SK $( \pm)$ phagemid that contained random $H$. glycines cDNA inserts was mass-excised from a Uni-ZAP XR library and cloned as plasmid in $E$. coli SOLR strain (Stratagene, La Jolla, CA, U.S.A.). It was discovered that treatment with isopropyl- $\beta$-D-thiogalactopyranoside (IPTG) induced some $H$. glycines cDNA clones in the $E$. coli SOLR host to express and secrete products that were able to degrade a CMC overlay. Secretion of CMC-degrading products was not detected, however, when the same pBluescript II SK ( \pm ) plasmid $H$. glycines cDNA library was cloned and IPTGinduced in an E. coli BL21 host strain (Novagen, Madison, WI, U.S.A.). Approximately 50 clear halos of CMC degrada- tion were produced per plate of approximately 10,000 transformed $E$. coli SOLR colonies (Fig. 1). Twenty CMCdegrading colonies among the $50 \mathrm{CMC}$-degrading colonies were chosen at random, and purified clones were obtained through two subsequent rounds of lifts and CMC screening.

To investigate whether any of the 20 CMC-degrading clones contained a cDNA insert that matched either HG-eng-1 or HG-eng-2, gene-specific primers (Table 1) were used in polymerase chain reaction (PCR) with each SOLR clone as template (Fig. 2). When the HG-eng-2 specific primer (GSS2) and a $\mathrm{T} 7$ vector primer were used to amplify plasmid inserts, all 20 CMC-degrading clones produced a 400-bp PCR product. The previously characterized HG-eng-2 cDNA clone (Smant et al. 1998) also produced a 400-bp PCR product upon

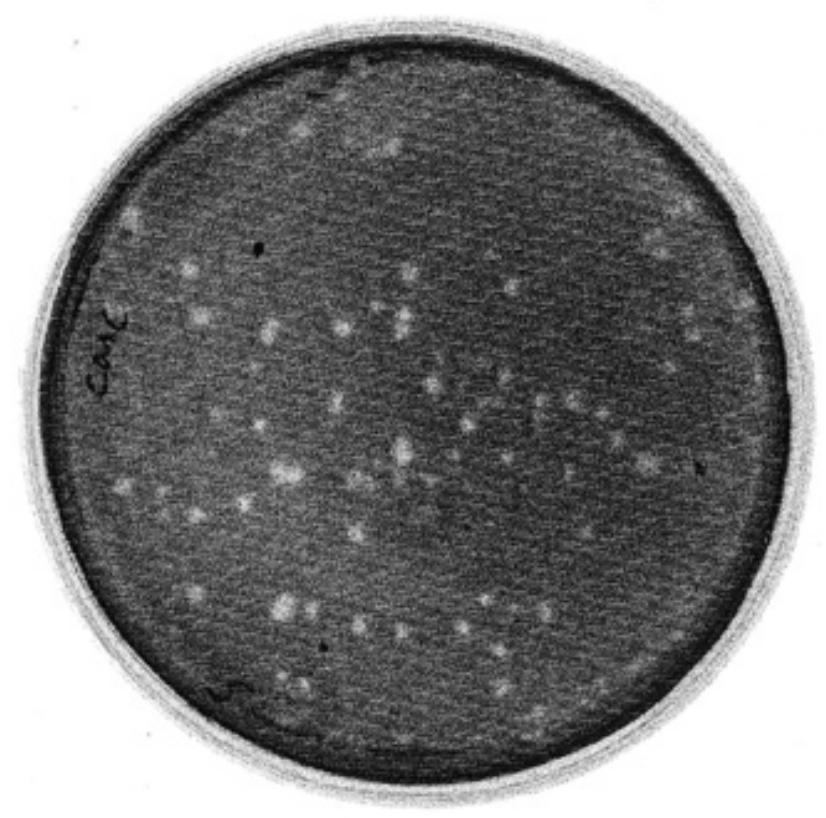

Fig. 1. Degradation of a carboxymethylcellulose substrate by $\beta-1,4$ endoglucanases from cloned cDNA of Heterodera glycines expressed in the Escherichia coli SOLR host strain. Clear zones represent bacterial colonies that secreted active recombinant $H$. glycines $\beta-1,4-$ endoglucanase.

Table 1. Primers used for identification of the $\beta$-1,4-endoglucanase cDNA and genomic clones from Heterodera glycines

\begin{tabular}{|c|c|c|}
\hline Primer name & Primer sequence & Remarks \\
\hline \multicolumn{3}{|c|}{$\begin{array}{l}\text { Primers used for character- } \\
\text { izing SOLR cDNA } \\
\text { clones }\end{array}$} \\
\hline GSS2 & 5'-TGCGAAGCGTCTAGCAACGGTAATCTGA-3' & Based on HG-eng-2 sequence; sense strand \\
\hline eng1-link & 5'-AACCAGAGGAGCCCGAACTT-3' & Based on HG-eng-1 linker sequence; sense strand \\
\hline $\mathrm{T} 3$ & 5'-ATTAACCCTCACTAAAG-3' & $\begin{array}{l}\text { Based on pBluescript SK (Stratagene, La Jolla, CA, } \\
\text { U.S.A.) vector sequence }\end{array}$ \\
\hline $\mathrm{T} 7$ & 5'-TAATACGACTCACTATAGGG-3' & Based on pBluescript SK vector sequence \\
\hline \multicolumn{3}{|c|}{$\begin{array}{l}\text { Primers used for character- } \\
\text { izing genomic clones }\end{array}$} \\
\hline GSS3 & 5'ATGCTTTGCGATTTATCTGCGCTCAAAA-3' & $\begin{array}{l}\text { Based on HG-eng-2 catalytic domain sequence; for } \\
\text { probe labeling }\end{array}$ \\
\hline eng2-5' & 5'-ATTTATTTGAAGAGTATTTTTTTATTAAGA-3' & $\begin{array}{l}\text { HG-eng- } 2 \text { cDNA } 5^{\prime} \text { gene-specific primer; antisense } \\
\text { pos-0 to pos-30 }\end{array}$ \\
\hline eng $3-5^{\prime}$ & 5'-TTTTTAGATTGGGAGAAAATTAGTTGGAAT-3' & $\begin{array}{l}\text { HG-eng-3 cDNA } 5^{\prime} \text { gene-specific primer; antisense } \\
\text { pos-0 to pos-30 }\end{array}$ \\
\hline FIX_T3 & 5'-GCTCTAATACGACTCACTATAGGGCGTCGACTC-3' & Based on Lambda FIX-II (Stratagene) vector sequence \\
\hline FIX_T7 & 5'-CGCGAGCTCAATTAACCCTCACTAAAGGGAGTC-3' & Based on Lambda FIX-II vector sequence \\
\hline
\end{tabular}


amplification by GSS2 and T7 primers. In contrast, PCR of the same 20 clones with the HG-eng-1 specific primer (eng1link) and a T7 primer produced no detectable amplification products. The results suggested that the 20 clones recovered by CMC screening were closely related to HG-eng-2.

DNA sequence of plasmid from the 20 selected CMCdegrading $H$. glycines cDNA clones indicated that all cDNA inserts encoded a complete signal peptide and a complete family 5 endoglucanase catalytic domain. The $3^{\prime}$ and $5^{\prime}$ RACE were conducted to obtain and verify the $3^{\prime}$ and $5^{\prime}$ UTR of each cDNA sequence (Fig. 3). None of the isolated full-length endoglucanase cDNA clones contained the peptide linker and CBD domains that are present in HG-eng-1 (Smant et al. 1998). Two types of full-length sequences were obtained from the $20 \mathrm{CMC}$-degrading cDNA clones: those that were $100 \%$ identical in nucleotide sequence to the full-length HG-eng-2 cDNA and those that were highly similar to HG-eng-2 in peptide coding sequence but with a $5^{\prime}$ UTR that was significantly different from HG-eng-2 (Fig. 3). The clones of the second type of endoglucanase cDNA from $H$. glycines were all identical in nucleotide sequence and considered to be a homologs of HG-eng-2 that was designated HG-eng-3 (AF044210). HGeng-2 and HG-eng-3 were $99.47 \%$ identical in nucleotide sequence, spanning the 1,128-bp region from the translation start codon (ATG) to the poly A(+) tail and $99.06 \%$ identical in predicted amino acid sequence. The $5^{\prime}$ UTR of HG-eng-2 and HG-eng-3 cDNA were 63 and 83 bp, respectively, and
$60 \%$ identical in sequence (Fig. 3). Sequence of the $3^{\prime}$ UTR of HG-eng-3 was identical to that reported for HG-eng-2 (Yan et al. 1998).

\section{Analysis of nematode endoglucanase reading frames.}

Two candidate cDNA clones were chosen to analyze the predicted expression and secretion of nematode endoglucanases in the E. coli SOLR strain. In theory, $H$. glycines cDNA excised from the Uni-ZAP library should have contained the upstream pBluescript $\beta$-galactosidase fused in-frame with the nematode cDNA insert for proper expression and secretion in the E. coli host. Plasmids prepared from two strong CMCdegrading SOLR clones representing HG-eng-2 (SOLR1) and HG-eng-3 (SOLR22) were sequenced to evaluate the junction between the $\beta$-galactosidase coding sequence and the downstream nematode endoglucanase coding sequence. Sequence analysis suggested that the cellulase activity from SOLR1 (HG-eng-2) was derived from an in-frame fusion of $\beta$ galactosidase and soybean cyst nematode endoglucanase that could be secreted (Fig. 4). In contrast, the SOLR22 (HG-eng3) clone contained a stop codon (TGA) $15 \mathrm{bp}$ upstream of the HG-eng-3 translation start site. The occurrence of this stop codon also was independently verified by $5^{\prime}$ RACE experiments by an antisense primer derived from the HG-eng-3 signal peptide region and a $3^{\prime}$ RACE experiment by a sense primer from the upstream region of the full-length HG-eng-3 cDNA.

\section{HG-eng-1 cDNA clone}

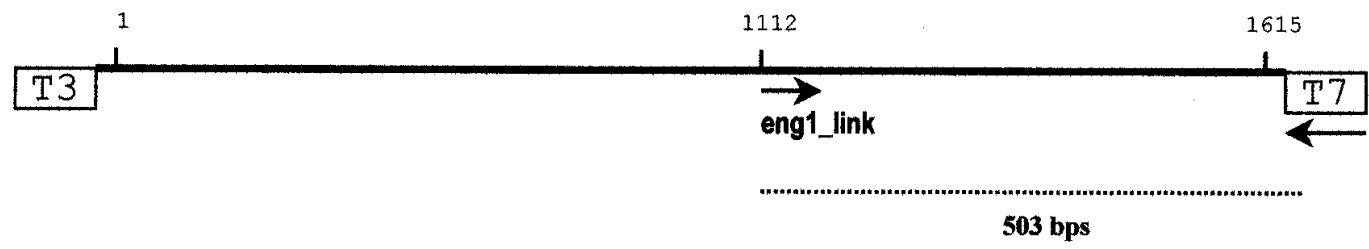

HG-eng-2 cDNA clone

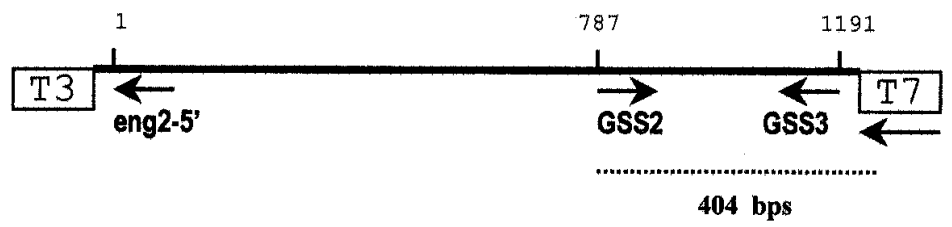

HG-eng-3 cDNA clone

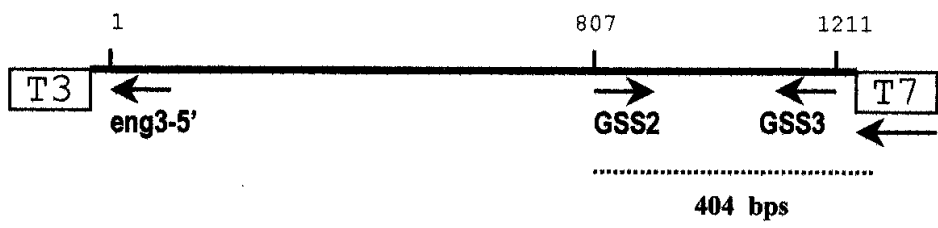

Fig. 2. Maps of primers listed in Table 1 used for selective polymerase chain reaction amplification of $\beta$-1,4-endoglucanase (eng) cDNA from Heterodera glycines. 


\section{Genomic organization of HG-eng-2 and HG-eng-3.}

Probes specific to HG-eng-1 and HG-eng-2 identified 18 and 24 plaques, respectively, from about 10,000 PFU of a $H$. glycines genomic library. Since HG-eng-2 and HG-eng-3 had strong sequence identity, the genomic clones isolated with the HG-eng-2 probe were analyzed for the presence of HG-eng-3. A $14.2-\mathrm{kb} H$. glycines genomic clone (10HB_1) and a $14.3-\mathrm{kb}$ genomic clone (15HB_4) were chosen for this analysis because restriction mapping results suggested that two HG-eng copies were present in each clone (Fig. 5).

With the exception of SmaI, all restriction digests of the 10HB_1 $\mathrm{H}$. glycines genomic fragment produced two strong bands on DNA blots that hybridized with the GSS3 probe of HG-eng-2 (Fig. 5). With the use of the 10HB_1 genomic fragment as template, primers eng2-5' and FIX_T7 generated a 1.0-kb DNA product, whereas primers eng3-5' and FIX_T3 generated an 0.8-kb DNA fragment (Fig. 6). These results suggested that the HG-eng-2 and HG-eng-3 genes were organized in a tail-to-tail transcriptional orientation on the 10HB_1 genomic fragment. Flanking Lambda Fix II (Stratagene) vector primers, primers derived from the HGeng-2 and HG-eng-3 cDNA coding regions, and 10HB_1 as template were used to obtain and compare the complete genomic sequence of the endoglucanase coding regions and $5^{\prime}$ flanking regions of HG-eng-2 and HG-eng-3 (GenBank acces-

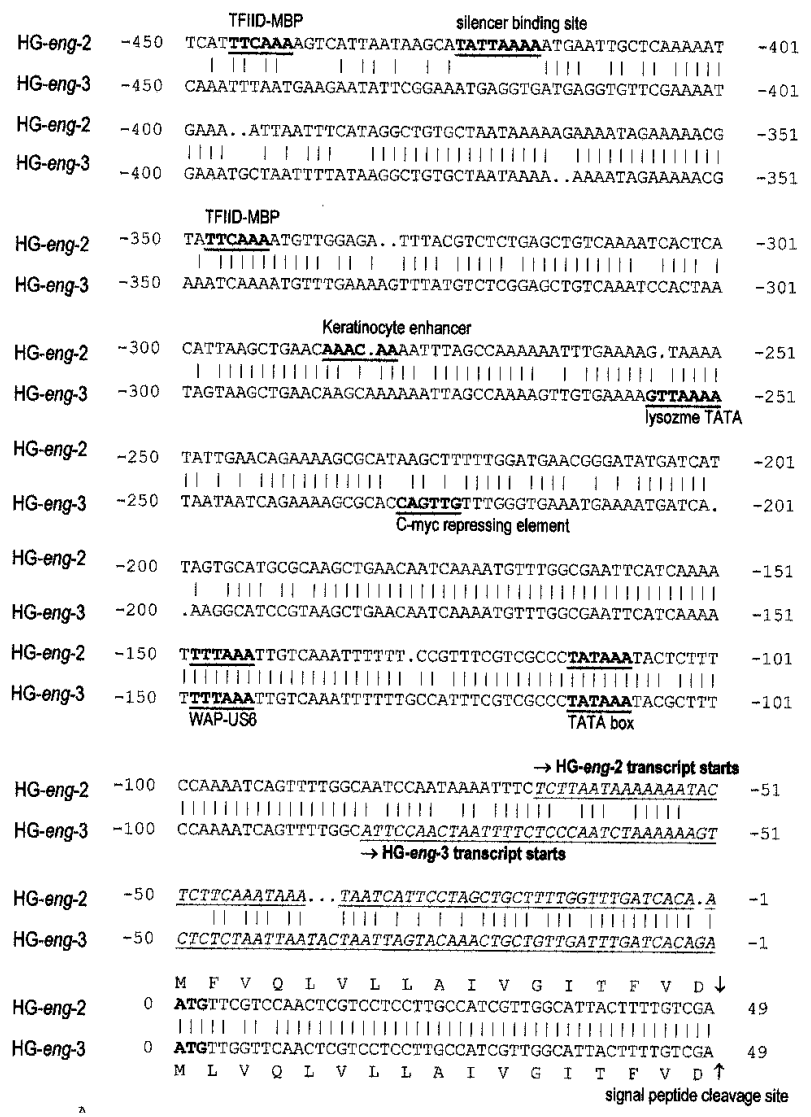

Fig. 3. DNA sequences of predicted secretion signal peptides, $5^{\prime}$ untranslated regions, and $5^{\prime}$ flanking regions of the transcription start points of two $\beta-1,4-e n d o g l u c a n a s e$ genes from Heterodera glycines, HGeng-2 and HG-eng-3. Bold denotes predicted transcription and translation (ATG) start points and regulatory consensus cis elements. sion nos. AF052734 and AF056048, respectively) (Fig. 3).

The genomic coding regions of HG-eng-2 and HG-eng-3 (2,260 nucleotides [nt] each) had an identical intron nucleotide sequence, identical intron splicing consensus sequences, and were $99.51 \%$ identical in their exon nucleotide sequence throughout the coding region (from the ATG translation start to the polyadenylation site). In contrast, the -1 to $-83 \mathrm{nt}$ (UTR) region was only $60 \%$ identical between HG-eng- 2 and HG-eng-3 (Fig. 3). Interestingly, the nucleotide sequence identity percentage between HG-eng- 2 and HG-eng-3 was highly conserved (98\%) in the 105-bp region ( -84 to -188$)$ upstream of the translation start site of HG-eng-3. This highly conserved genomic region had TATA box and WAP-US6 (Lubon and Hennighausen 1987) regulatory consensus cis elements for HG-eng-2 and HG-eng-3. The TATA box of HGeng-2 was located $40 \mathrm{bp}$ upstream of the transcription start point (tsp), whereas in HG-eng-3, the TATA box was located $25 \mathrm{bp}$ upstream of the $t s p$. Nucleotide sequence identity declined to $69.4 \%$ between HG-eng-2 and HG-eng-3, from -189 to $-450 \mathrm{bp}$ of genomic DNA. Sequence of this upstream region predicted several unique transcriptional cis elements in the HG-eng-2 and HG-eng-3 genomic sequence (Fig. 3).

All restriction digests of the 15HB_4 H. glycines genomic fragment, except for $N d e I$, produced two distinctive hybridized bands when probed with labeled GSS3 (HG-eng-2) primer (Fig. 5). The NdeI enzyme digestion apparently displayed only one hybridized band because of the similar size of the two hybridizing DNA fragments. The Southern blots confirmed that there were two endoglucanase genes within the $15 \mathrm{HB} \_4$ genomic clone. Only primer eng $2-5^{\prime}$ could produce distinctive PCR products when the 8.7- and 5.6-kb PstI subclones of 15HB_4 were used as template, suggesting the presence of one copy of HG-eng-2 on each of the two subclones (Fig. 6). The endoglucanase coding regions from the two subclones were identical in nucleotide sequence to the previously characterized HG-eng-2 genomic sequence (Yan et al. 1998). Primers eng2-5' and T3 generated a 3.0-kb PCR product from the 8.7-kb subclone (Fig. 6). The direction of transcription of HG-eng-2 in the 8.7-kb subclone was apparently away from the intergenic PstI site. Primers eng2-5' and T3 (pBluescript KS vector) amplified a distinctive $3.5-\mathrm{kb}$ product from the $5.6-\mathrm{kb}$ subclone, suggesting that transcription of HG-eng-2 in the 5.6-kb subclone also was away from the intergenic PstI site. These results indicated that the two HG-eng-2 genes were arranged head to head and separated by approximately $6.5 \mathrm{~kb}$ in the 15HB_4 genomic clone (Fig. 6).

\section{DISCUSSION}

The observation that the HG-eng-2 and HG-eng-3 endoglucanase cDNA clones could be effectively isolated by functional screening on CMC medium suggested that both genes were actively transcribed in preparasitic second-stage juveniles of $H$. glycines. Differences in the nucleotide identity and position of some transcriptional cis elements in the -189- to -450-bp regions of HG-eng-2 and HG-eng-3 suggested that each gene may be regulated differently during plant parasitism. The highly conserved nucleotide identity in the $105 \mathrm{bp}$ immediately upstream of the tsp of HG-eng-2 and HG-eng-3, however, suggests the potential importance of this region in the global regulation of endoglucanase gene expression in $H$. 
glycines. Conservation of the exon and intron DNA sequence, intron location, and close genome proximity combined with an opposite transcriptional orientation suggest that HG-eng-2 and HG-eng-3 were the products of gene duplication and inversion. As far as we know, this is the first report of this type of organization of parasitism genes within a plant-parasitic nematode genome. The complete conservation of the intron sequence between HG-eng-2 and HG-eng-3 with significant divergence in the first exon sequence is unusual because it is expected that exon sequences would be subject to more stringent selection compared with introns (Gilbert et al. 1986). Coupled with the identical 3' UTR nucleotide sequence identi- fied between HG-eng-2 and HG-eng-3, these data suggest a very recent duplication and inversion event.

Given a $H$. glycines genome size of $92.5 \mathrm{mb}$ (Opperman and Bird 1998) and assuming an average genomic insert size of $15 \mathrm{~kb}$ (yielding 6,166 hypothetical genomic clones) and random distribution of eng genes within the nematode genome, genomic library screening results (42 eng clones among 10,000 PFU) would predict approximately 26 eng genes $(6,166 \times 42 / 10,000)$ within the $H$. glycines genome. This prediction may be skewed in one direction or the other, however, because the eng genes do not appear to be randomly distributed within the $H$. glycines genome. The relatively

\section{SOLR1 clone}

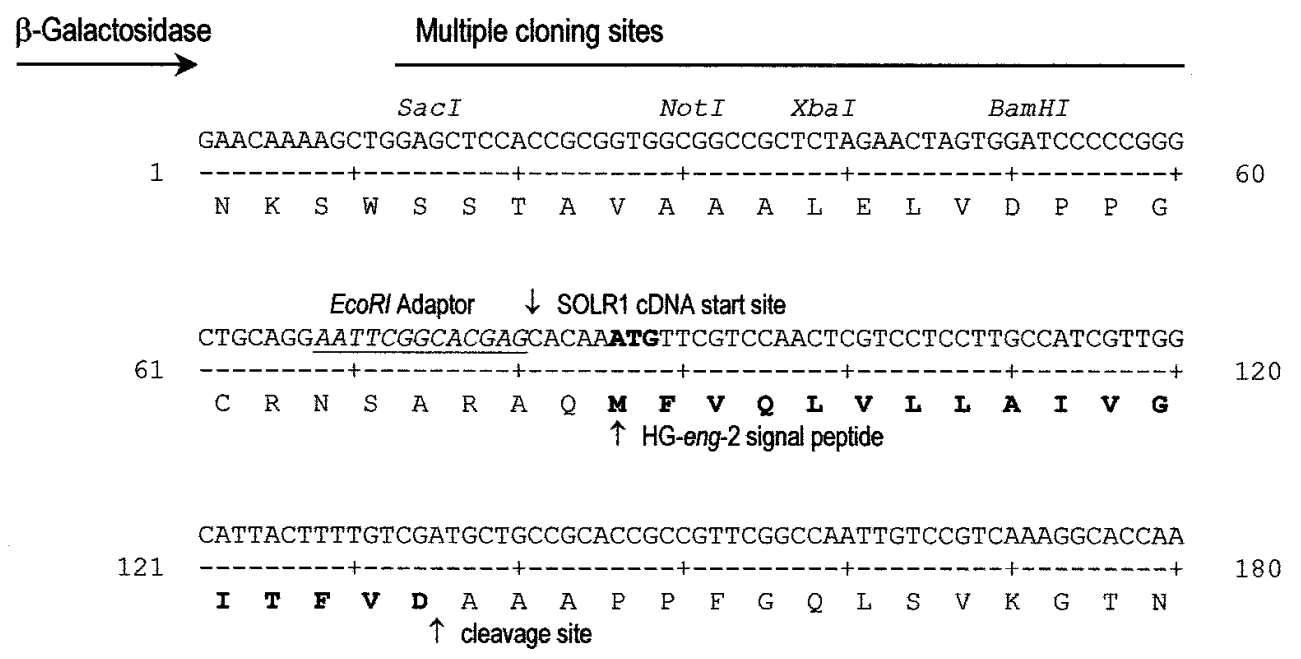

\section{SOLR22 clone}

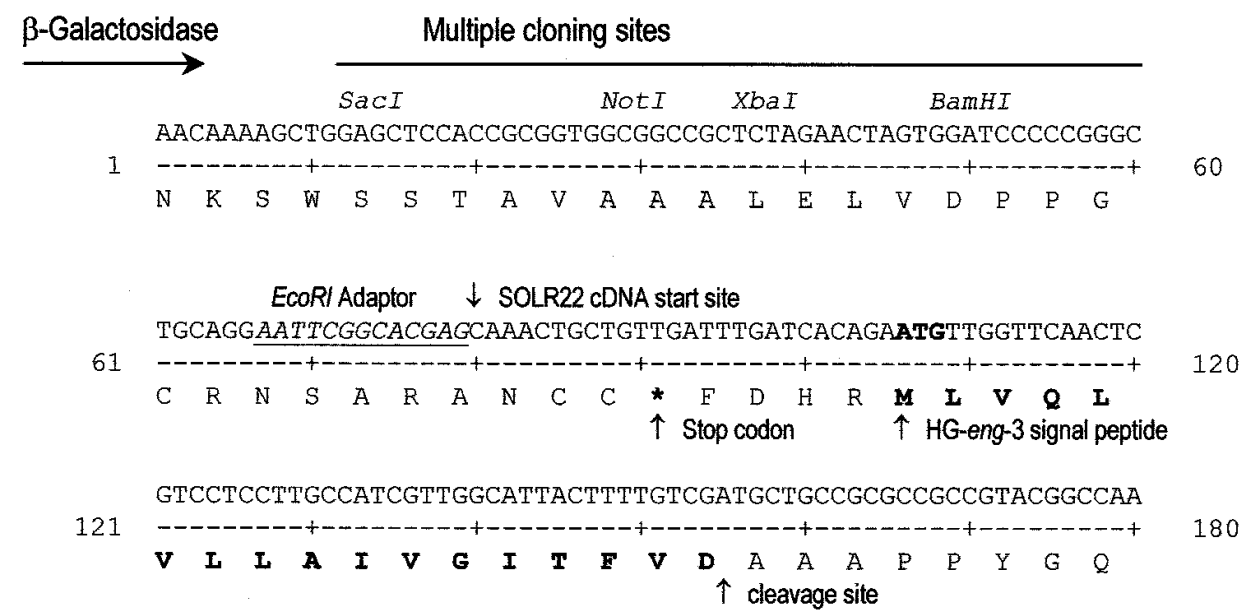

Fig. 4. Nucleotide and predicted amino acid sequences of the junction between the $\beta$-galactosidase of the pBluescript II SK ( \pm ) vector and the HG-eng-2 and HG-eng-3 cDNA inserts that produced secreted, active nematode endoglucanase in Escherichia coli SOLR1 and SOLR22 clones, respectively. Sequence of the SOLR1 clone indicates an in-frame fusion of the $\beta$-galactosidase with HG-eng-2, whereas HG-eng- 3 is not in-frame with $\beta$-galactosidase in the SOLR22 clone. 
close proximity of HG-eng-2 and HG-eng-3 (about $8 \mathrm{~kb}$ apart) suggests that endoglucanase genes may be clustered within the H. glycines genome. This is supported by the presence of two copies of HG-eng- 2 that are approximately $6.5 \mathrm{~kb}$ apart on a separate genomic clone. It has been proposed that clustered genes are usually within a few kilobases of each other and are often mutually inverted in an unpredictable pattern and connected by nonconserved DNA (Graham 1995). Major protein genes are often found in tandem repeats, and models have been proposed to illustrate the origin of such patterns (Scott et al. 1988). One consideration is that the amplification of progenitor endoglucanase genes within the $H$. glycines genome may have provided the nematode with the requisite amount of cellulase for successful parasitism within host plants. Although endoglucanase expression levels are relatively high in $H$. glycines (deBoer et al. 1999; Wang et al. 1999), it remains unclear whether these levels are the result of the expression of multiple copies of endoglucanase genes or the expression of a few endoglucanase genes driven by efficient promoters.

The functional screening approach provides a relatively rapid method to isolate cDNA clones of nematode genes that encode enzymes that can hydrolyze complex carbohydrates. The ability to degrade CMC has been used previously to isolate clones of cellulase genes from the major cellulolytic bacteria in bovine rumen, Fibrobacter succinogenes, and from the filamentous fungus, Trichoderma reesei (Malburg and Forsberg 1993; Saloheimo et al. 1994). Selection of expressed endoglucanase genes by functional screening is dependent upon secretion of the gene product from host cells into the media, suggesting a requirement for an appropriate signal peptide with the cloned cDNA. A yeast host (Saccharomyces cerevisiae) is recommended for functional screening of eukaryotic genes (Margolles-Clark et al. 1996), but the use of pBluescript II SK $( \pm)$ plasmid containing cDNA inserts in the E. coli SOLR host was successful in isolating HG-eng-2 and HG-eng-3 from $H$. glycines. Recombinant nematode endoglucanase proteins expressed and secreted by E. coli were expected to be fused in-frame with the $\beta$-galactosidase and its signal peptide expected to be present in the pBluescript plasmid that was excised from the original lambda Uni-ZAP library. It was not surprising that the in-frame fusion of HGeng-2 in SOLR1 produced an active $\beta$-gal-endoglucanase fusion protein that was secreted by $E$. coli. Secretion of active HG-eng-3 in clone SOLR22 in the presence of an upstream stop codon, however, was unexpected. The signal peptide of the HG-eng-3 cDNA insert may have promoted independent translation and secretion of active endoglucanase from the transcript of the SOLR22 clone, but this type of expression has been observed only in mammalian systems (Sakai et al. 1998). The apparent close similarity and potential origins of the nematode endoglucanase genes to those of bacteria (Davis et al. 2000; Smant et al. 1998; Yan et al. 1998) may allow recognition, translation, and secretion of nematode endoglucanase genes in a bacterial system. The choice of the $E$. coli host strain also appears to be important, although it remains unclear why the nematode endoglucanases were secreted from the SOLR strain but not from the BL21 strain.
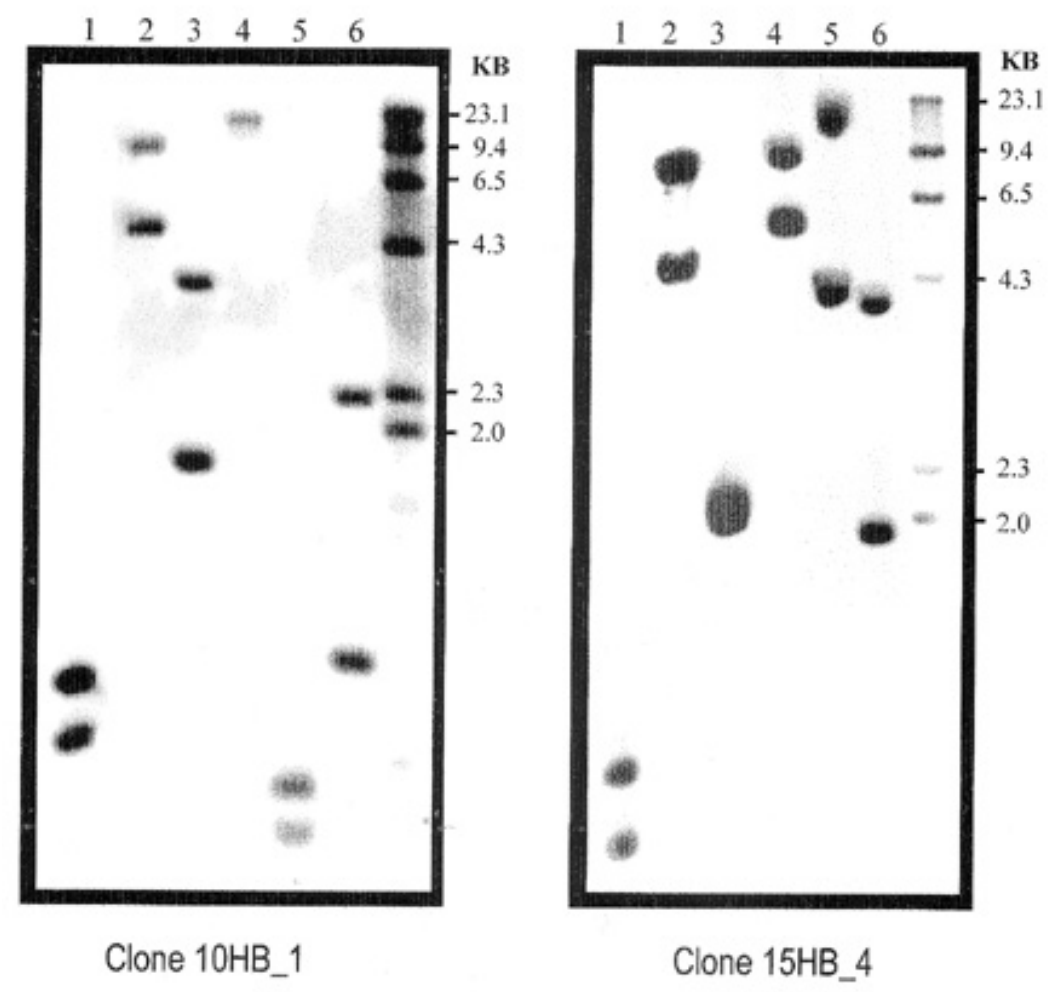

Fig. 5. Left, Southern blot of the 10HB_1 (14.2-kb) genomic clone of Heterodera glycines DNA digested with HindIII (lane 1), ClaI (lane 2), PvuII (lane 3), SmaI (lane 4), MspI (lane 5), and HaeII (lane 6). A DNA ladder is in lane 7. Right, Southern blot of the 15HB_4 (14.3-kb) genomic clone of $H$. glycines DNA digested with HindIII (lane 1), SacI (lane 2), NdeI (lane 3), PstI (lane 4), ClaI (lane 5), and PvuII (lane 6). A DNA ladder is in lane 7. A digoxigenin-labeled HG-eng-2-specific probe made with primer GSS3 hybridized to two fragments in all lanes except 4 and 3 of the left and right blots, respectively, suggesting the presence of two endoglucanase genes on the 10HB_1 and 15HB_4 H. glycines genomic clones. 
It also must be noted that HG-eng-1 was not recovered from the 20 cDNA clones chosen at random from the total number of $H$. glycines clones that were able to degrade CMC. This finding may be a function of the expression system itself because expression of functional HG-eng-1 within E. coli was achieved with the pET (Novagen) expression system (Smant et al. 1998; Wang et al. 1999). eng-1 expressed by the pET system, however, did not include the signal peptide and formed inclusion bodies in its E. coli host (Wang et al. 1999). At present, secretion of HG-eng-1 from an E. coli host has not been reported in any expression system. The apparent lack of secretion may be a result of the presence of the CBD on HGeng-1 or the absence of an appropriate signal peptide. More exhaustive analysis of CMC-degrading clones in the SOLR system or the choice of an alternative expression system may be necessary to recover the full complement of cDNA clones that encode cellulolytic enzymes in any given plant-parasitic nematode cDNA library.

The natural enzymatic conversion of cellulose into subunits is complex because of the physical nature of the plant cell wall. Organisms that hydrolyze crystalline cellulose generally secrete an array of enzymes with different substrate specificities and modes of action that act in synergy to degrade cell walls. T. reesei cellulases can be divided into three major categories: cellobiohydrolases, $\beta$-1,4-endo-glucanases, and $1,4-\beta$-D-glucosidases (Saloheimo et al. 1994). Endogenous cellulases other than $\beta$-1,4-endoglucanases have not been reported in plant-parasitic nematodes. Four distinct xylanase genes from $F$. succinogenes were identified by functional screening of a cDNA expression library on media containing remazol brilliant blue xylan (Malburg et al. 1993). Incorporation of different complex carbohydrate substrates into media (Dingle et al. 1953) used for functional screening of cDNA clones from plant-parasitic nematodes may provide a rapid means to identify other endogenous enzymes involved in nematode parasitism of plants.

\section{MATERIALS AND METHODS}

\section{H. glycines cDNA library construction.}

Total RNA was prepared from $1 \mathrm{ml}$ of packed $H$. glycines preparasitic second-stage juveniles with a Cs-TFA RNA extraction kit (Amersham Pharmacia Biotech, Piscataway, NJ, U.S.A.). A 50-bp linker primer (5'-GAGAGAGAGAGAGAGAGAGAACTAGTCTCGAG(T) $)_{18^{-}} 3^{\prime}$ ) was used to initiate synthesis of first-strand cDNA for library construction. The $H$. glycines cDNA library was constructed in the lambda UniZAP XR vector and E. coli XL1-Blue $\mathrm{MRF}^{\prime}$ host strain (Stratagene). The primary library contained $1.4 \times 10^{6} \mathrm{PFU}$, and the estimated amplified titer was $9.2 \times 10^{9} \mathrm{PFU} / \mathrm{ml}$.

\section{In vivo excision of cDNA library.}

pBluescript II SK ( \pm ) phagemid from the $H$. glycines UniZAP cDNA library was mass-excised in vivo with the ExAssist-SOLR system (Stratagene). Two hundred microliters of E. coli XL1-Blue $\mathrm{MRF}^{\prime}$ cells at optical density (OD) at 600 $\mathrm{nm}$ equals 5.0 in $10 \mathrm{mM} \mathrm{MgSO}$, $200 \mu \mathrm{l}$ of $H$. glycines cDNA library phage stock $\left(1.8 \times 10^{9} \mathrm{PFU}\right.$ total $)$, and $1 \mu \mathrm{l}$ of ExAssist helper phage $\left(>1 \times 10^{6} \mathrm{PFU} / \mathrm{ml}\right)$ were mixed and incubated at $37^{\circ} \mathrm{C}$ for $15 \mathrm{~min}$ (the $H$. glycines cDNA library phage stock was added in excess to ensure statistical representation of the excised cDNA library). Three milliliters of Luria-Bertani (LB) broth were subsequently added to the mixture and incubated for $3 \mathrm{~h}$ at $37^{\circ} \mathrm{C}$ with shaking. The suspension was then heated at $70^{\circ} \mathrm{C}$ for $15 \mathrm{~min}$ and centrifuged, and the supernatant that contained the excised phagemid cDNA library stock was collected.

\section{Genomic clone 10HB_1}

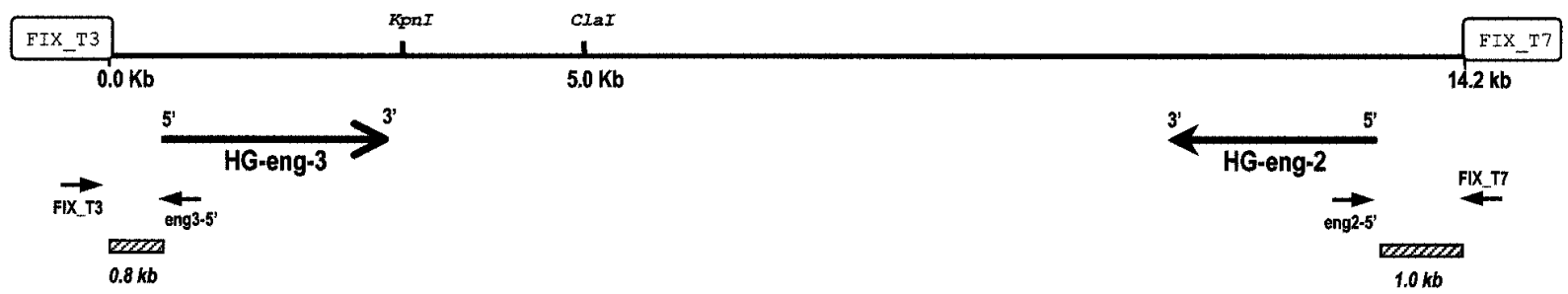

\section{Genomic clone 15HB_4}

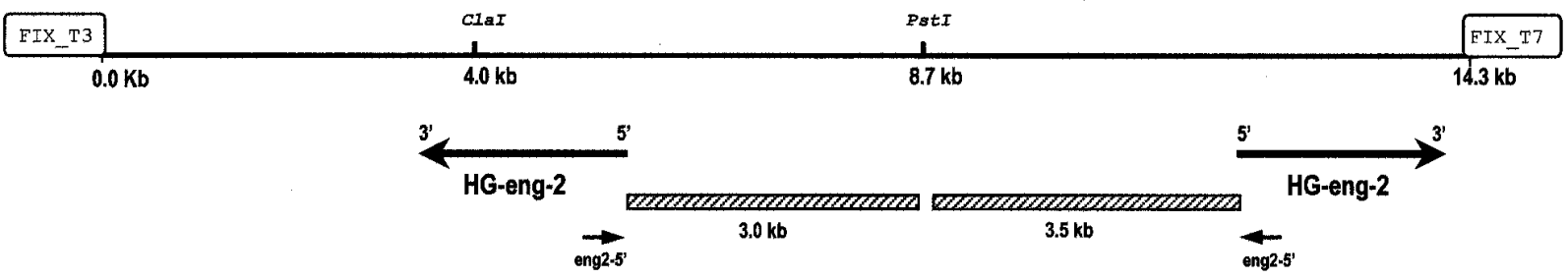

Fig. 6. Maps of primers listed in Table 1 that were used for selective polymerase chain reaction amplification of $\beta$-1,4-endoglucanase (eng) genes from the $10 \mathrm{HB} \_1(14.2-\mathrm{kb})$ and $15 \mathrm{HB} \_4(14.3-\mathrm{kb})$ genomic clones of Heterodera glycines DNA. The HG-eng-2 and HG-eng-3 genes are organized in a tailto-tail orientation and separated by approximately $8.0 \mathrm{~kb}$ on clone $10 \mathrm{HB} \_1$, and two copies of HG-eng-2 are oriented head to head and separated by approximately $6.5 \mathrm{~kb}$ on clone $15 \mathrm{HB} \_4$. 


\section{H. glycines cDNA library expression in E. coli.}

The E. coli SOLR strain (genotype: e14-(mcrA), $\Delta($ mcrCBhsdSMR-mrr)171, sbcC, recB, recJ, umuC::Tn5 $\left(\operatorname{kan}^{\mathrm{r}}\right), u v r C$, lac, gyrA96, relA1, thi-1, endA1, lambda ${ }^{\mathrm{R}}\left[\mathrm{F}^{\prime}\right.$ proAB, lacl ${ }^{\mathrm{q}}$ $Z \Delta M 15]$ Su-nonsuppressing) has been optimized by the manufacturer (Stratagene) for replication of pBluescript II SK $( \pm)$ phagemid that was excised from a Uni-ZAP cDNA library. Two hundred microliters of freshly grown $E$. coli SOLR strain $\left(\mathrm{OD}_{600}=1.0\right)$ and $1 \mu \mathrm{l}$ of $H$. glycines cDNA phagemid stock were mixed and incubated at $37^{\circ} \mathrm{C}$ for $15 \mathrm{~min}$. A volume of 0.1 to $5.0 \mu \mathrm{l}$ of $E$. coli SOLR host harboring pBluescript plasmid of the $H$. glycines cDNA library was transferred to $150-\mathrm{mm}$ petri plates of LB medium containing $100 \mu \mathrm{g}$ of ampicillin per milliliter and incubated at $37^{\circ} \mathrm{C}$ for $8 \mathrm{~h}$ or until single colonies became visible (approximately 10,000 colonies per plate). The amount of transformed E. coli necessary to achieve single-clone representation was determined in each experiment. Duplicate lifts of the colonies on 137-mm Hybond-N membranes (Amersham Pharmacia Biotech) were inverted on LB plates containing $100 \mu \mathrm{g}$ of ampicillin per milliter and $2 \mathrm{mM}$ IPTG to induce the expression of cloned cDNA at $30^{\circ} \mathrm{C}$ until each colony was about $1.5 \mathrm{~mm}$ in diameter (about $14 \mathrm{~h}$ ). A strain of E. coli recommended for protein expression, BL21, also was transformed with pBluescript II SK $( \pm)$ plasmid of the $H$. glycines cDNA library and was plated, lifted, and IPTG-induced, as described above.

\section{Screening for cellulolytic activity.}

A solution of $0.2 \%$ CMC in PCA buffer $\left(128 \mathrm{mM} \mathrm{K}_{2} \mathrm{HPO}_{4}\right.$ adjusted to $\mathrm{pH} 5.2$ with $1 \mathrm{M}$ citric acid) was mixed 1:1 with a solution of $2.0 \%$ agarose in PCA buffer and plated on 150-mm petri plates (Mateos et al. 1992). Membrane lifts of IPTGinduced $E$. coli harboring $H$. glycines cDNA were inverted on individual plates of CMC media and incubated at $28^{\circ} \mathrm{C}$ for $4 \mathrm{~h}$. Membranes were removed from the CMC plates, and the surface of each plate was gently rinsed with sterile water to remove bacterial debris and flooded with $0.1 \%$ (wt/vol) Congo red solution in water for $15 \mathrm{~min}$. The Congo red solution was rinsed from the plate, and a solution of $1 \mathrm{M} \mathrm{NaCl}$ was added (for about $10 \mathrm{~min}$ ) to the surface of the plate until clear halos of CMC degradation could be observed against the Congo red background. The CMC degradation zones were aligned with the duplicate lifts to isolate colonies that expressed cellulolytic activity.

\section{Analysis of cellulolytic clones.}

Only the E. coli SOLR host transformed with the $H$. glycines cDNA library secreted products that could degrade $\mathrm{CMC}$. Twenty colonies were chosen at random from the approximately $50 \mathrm{CMC}$-degrading colonies present among a total of about 10,000 E. coli colonies. Single CMC-degrading isolates were purified from each of the 20 colonies through two subsequent rounds of lifts and CMC screening. Plasmid from each clone was used as template in PCR reactions to assay for the presence of $H$. glycines endoglucanase cDNA. Amplifications of all 20 plasmids were conducted with the HG-eng-2-specific primer, GSS2 (Table 1 and Fig. 2); a T7 primer; a HG-eng-1-specific primer, eng1-link; and a $\mathrm{T} 7$ primer. All 20 cDNA inserts were amplified only by the HGeng-2 primer set, and each isolated plasmid insert was fully sequenced utilizing the $\mathrm{T} 3$ and $\mathrm{T} 7$ primers of pBluescript II
KS. Primers derived from the unique $5^{\prime}$ UTR sequences of HG-eng-2 and HG-eng-3 (Fig. 3) were used to obtain fulllength cDNA clones with total RNA extracted from $H$. glycines second-stage juveniles as template in $5^{\prime}$ and $3^{\prime}$ RACE where appropriate for each partial cDNA derived from the 20 original clones.

Plasmids from two strong CMC-degrading clones representing HG-eng-2 (SOLR1) and HG-eng-3 (SOLR22) were sequenced with pBluescript II KS reverse primer (5'GGAACAGCTATGACCATG-3') and corresponding engspecific forward primers to analyze the junction between the $\beta$-galactosidase coding region and the downstream endoglucanase coding sequence.

\section{Isolation and analysis of HG-eng-2 and HG-eng-3 genomic clones.}

The $H$. glycines genomic clones were recovered by screening a Lambda Fix II genomic library, as described previously (Yan et al. 1998) with a HG-eng-2-specific cDNA probe that was prepared with primers GSS3 and GSS2 (Table 1 and Fig. 2) and digoxygenin (DIG) labeling (Roche Molecular Biochemicals, Indianapolis, IN, U.S.A.). HG-eng-2-positive genomic inserts were restriction mapped with the 28-bp GSS3 primer (Table 1) that was $3^{\prime}$ end labeled with DIG as a probe on Southern blots (Fig. 5).

The genomic clones $10 \mathrm{HB} \_1$ and $15 \mathrm{HB} \_4$ were chosen for further analysis because restriction mapping data indicated the presence of two copies of HG-eng-2-like genes on each genomic fragment (Fig. 5). The limited similarity in the $5^{\prime}$ UTR between HG-eng-2 and HG-eng-3 (Fig. 3) was used to design the gene-specific primers eng2-5' and eng3-5' (Table 1) to differentiate between HG-eng-2 and HG-eng-3. Primers eng2-5' and eng3-5' were used with primers FIX_T7 and FIX_T3 (Table 1 and Fig. 6) to initially determine the identity and orientation of the endoglucanase genes on the two $H$. glycines genomic clones.

ClaI digestion of $H$. glycines genomic DNA insert 10HB_1 yielded 5.0- and 9.2-kb subfragments (Figs. 5 and 6) that were subcloned into the NotI and ClaI sites of pBluescript II KS, respectively. PstI digestion of the 15HB_4 insert yielded 8.7and 5.6-kb subfragments (Figs. 5 and 6) that were cloned into the NotI and PstI sites of plasmid pBluescript II KS, respectively. Complete genomic sequence of the endoglucanase coding regions and 5' flanking regions of HG-eng-2 and HGeng-3 were obtained and compared.

\section{ACKNOWLEDGMENTS}

This research was supported by the North Carolina Agricultural Research Service, the U.S. Department of Agriculture under NRI grant 9537302-1918, and the United Soybean Board under grant 400-41-52. Support also was provided from the Dutch Potato Board; the Dutch Technology Foundation coordinated by the Life Science Foundation; European Community grants BIO2-CT92-0239, BIO4-CT96-0318, and FAIR1-CT95-0905; and the North Atlantic Treaty Organization Award CRG931004.

\section{LITERATURE CITED}

Barras, F., Gijsegem, F., and Chatterjee, A. K. 1994. Extracellular enzymes and pathogenesis of soft-rot Erwinia. Annu. Rev. Phytopathol. 32:201-234.

Coughlan, M. P. 1985. The properties of fungal and bacterial cellulases 
with comment on their production and application. Biotechnol. Genet. Eng. Rev. 3:39-109.

Davis, E. L., Hussey, R. S., Baum, T. J., Bakker, J., Schots, A., Rosso, M. N., and Abad, P.. 2000. Nematode parasitism genes. Annu. Rev. Phytopathol. 38:341-372.

de Boer, J. M., Overmars, H. A., Pomp, H. R., Davis, E. L., Zilverentant, J. F., Jacoline, F., Goverse, A., Smant, G., Stokkermans, J., Hussey, R. S., Gommers, F. J., Bakker, J., and Schots, A. F.. 1996. Production and characterization of monoclonal antibodies to antigens from second stage juveniles of the potato cyst nematode, Globodera rostochiensis. Fundam. Appl. Nematol. 19:545-554.

de Boer, J. M., Yan, Y., Wang, X., Smant, G., Hussey, R. S., Davis, E. L., and Baum, T. J. 1999. Developmental expression of secretory beta1,4-endoglucanases in the subventral esophageal glands of Heterodera glycines. Mol. Plant-Microbe Interact. 12:663-669.

Deubert, K. H., and Rohde, R. A. 1971. Nematode enzymes. Pages 7390 in: Plant Parasitic Nematodes, Vol. 2. B. M. Zuckerman, W. F. Mai, and R. A. Rohde, eds. Academic Press, New York.

Dingle. J., Reid, W. W., and Solomons, G. L. 1953. The enzymic degradation of pectin and other polysaccharides. II. Application of the "cup-plate" assay to the estimation of enzymes. J. Sci. Food Agric. 4:149-155.

Gilbert, W., Marchionni, M., and McKnight, G. 1986. On the antiquity of introns. Cell 46:151-154.

Graham, G. J. 1995. Tandem genes and clustered genes. J. Theor. Biol. 175:71-87.

Lubon, H., and Hennighausen, L. 1987. Nuclear proteins from lactating mammary glands bind to the promoter of a milk protein gene. Nucleic Acids Res. 15:2103-21.

Malburg, L. M., and Forsberg, C. W. 1993. Fibrobacter succinogenes S85 possesses at least nine distinct glucanase genes. Can. J. Microbiol. 39:882-891.

Malburg, L. M., Smith, D. C., Schellhorn H. E., and Forsberg C. W. 1993. Fibrobacter succinogenes S85 has multiple xylanase genes. J. Appl. Bacteriol. 75:564-573.
Margolles-Clark, E., Tenkanen, M., Nakari-Setala, T., and Penttila, M. 1996. Cloning of genes encoding alpha-L-arabinofuranosidase and beta-xylosidase from Trichoderma reesei by expression in Saccharomyces cerevisiae. Appl. Environ. Microbiol. 62:3840-3846.

Mateos, P. F., Jimenez-Zurdo, J. I., Chen, J., Squartini, A. S., S., Haack, K., Martinez-Molina, E., Hubbell, D. H., and Dazzo, F. B. 1992. Cellassociated pectinolytic and cellulolytic enzymes in Rhizobium leguminosarum biovar trifoli. Appl. Environ. Microbiol. 58:1816-1822.

Opperman, C. H., and Bird, D. M. 1998. The soybean cyst nematode, Heterodera glycines: A genetic model system for the study of plantparasitic nematodes. Curr. Opin. Plant Biol. 1:342-346.

Sakai, N., Fukushima, H., Inui, K., Nishigaki, T., Yanagihara, I., Tatsumi, N., and Okada, S. 1998. Human galactocerebrosidase gene: Promoter analysis of the $5^{\prime}$-flanking region and structural organization. Biochim. Biophys. Acta 1396:62-7.

Saloheimo A., Henrissat, B., Hoffrein, A. M., Teleman, O., and Penttila, M. 1994. A novel, small endoglucanase gene, egl5, from Trichoderma reesei isolated by expression in yeast. Mol. Microbiol. 13:219-228.

Scott, G. K, Hayes, P. H., Fletcher, G. L., and Davies, P. L. 1988 Wolffish antifreeze protein genes are primarily organized as tandem repeats that each contains two genes in inverted orientation. Mol. Cell Biol. 8:3670-3675.

Smant, G., Stokkermans, J. P., Yan, Y., de Boer, J. M., Baum, T. J., Wang, X., Hussey, R. S., Gommers, F. J., Henrissat, B., Davis, E. L., Helder, J., Schots, A., and Bakker, J. 1998. Endogenous cellulases in animals: Isolation of beta-1,4-endoglucanase genes from two species of plant-parasitic cyst nematodes. Proc. Natl. Acad. Sci. USA 95:4906-4911.

Wang, X., Meyers, D., Yan, Y., Baum, T., Smant, G., Hussey, R., and Davis, E. 1999. In planta localization of a $\beta-1,4$-endoglucanase secreted by Heterodera glycines. Mol. Plant-Microbe Interact. 12:64-67.

Yan, Y., Smant, G., Stokkermans, J., Qin, L., Helder, J., Baum, T., Schots, A., and Davis, E. 1998. Genomic organization of four beta1,4-endoglucanase genes in plant-parasitic cyst nematodes and its evolutionary implications. Gene 220:61-70. 